\title{
Genetic structure among wild populations of Elliot's Pheasant Syrmaticus ellioti in China from mitochondrial DNA analyses
}

\author{
PING PING JIANG, YUN FA GE, QIU LEI LANG and PING DING
}

\begin{abstract}
Summary
Genetic structure among five populations of Elliot's Pheasant sampled from five different provinces - Anhui (AH), Zhejiang (ZJ), Fujian (FJ), Hunan (HN) and Guizhou (GZ) - was assayed using mitochondrial control region sequences from 33 individuals. Using AMOVA, we found a high level of haplotype variation within populations, and a degree of genetic structure among groups (GZ population relative to all others pooled). However, this difference was not statistically significant and little geographical structure was indicated among the remaining populations. Furthermore, using a rooted maximum parsimony tree, we found the sequences of the GZ population were largely grouped in their own branch, while sequences of the other four populations were interspersed among branches. We identified a lower level of gene flow between the GZ population and all others, a finding supported by significant $F_{S T}$ values. Conversely, we identified a larger amount of gene flow between the remaining four populations, particularly among the three easternmost populations (AH, ZJ and FJ). Given our results, further study should be focused on the GZ population and on management units for the purpose of maintaining the genetic structure of the species in the west of China.
\end{abstract}

\section{Introduction}

It has been documented that genetic structure among animal populations is fundamentally influenced by gene flow and historical demographic processes, as well as by natural selection and speciation (Laurent et al. 2003, Kvist et al. 1999). The genetic structure in species with a high potential for long-distance dispersal is expected to be homogeneous throughout a large geographical area. In contrast, low mobility causes significant genetic differences among populations (Newton 2003). The dispersal ability in birds seems to be good. The efficiency of gene flow is determined by dispersal ability together with geographic barriers. In addition to gene flow, historical demographic events are another important element in determining population structure, and should also be considered when an effective and sustainable management plan is developed.

Elliot's Pheasant (Syrmaticus ellioti), regarded as Vulnerable (http://www.redlist.org), is endemic to areas south of the Yangtze River in China. It is found in broad-leaved forest and mixed coniferous/broad-leaved forest habitats. In 1872 Swinhoe first found this species in southern Zhejiang and Anhui provinces. In the following year, Père David obtained specimens from Fujian province and instigated captive breeding of the species in Paris (Knoder 1983). Much research has been carried out on its conservation, morphology, breeding and ecology, especially since the 1980s (Delacour 1977, Long 1985, Ding and Zhuge 1988, Ding et al. 1990, Shi and Zheng 1997, Ding 1998). Its population size is believed to be declining because of continuing habitat loss, habitat fragmentation and hunting (Ding and Jiang 2000, BirdLife International 
2006). It has been concluded that both male and female Elliot's Pheasants disperse in spring, over distances of 1.5-2.1 km (Peng and Ding 2005). The relatively low mobility of the species highlights the need for research into possible variation in the genetic structure among populations of Elliot's Pheasant, a topic that has not previously been investigated.

Mitochondrial DNA (mtDNA) possesses several properties that make it uniquely suitable for the purpose of intraspecific phylogeographic analysis, including relatively high mutation rates, maternal inheritance and no recombination (Avise 200o). The control region (D-loop region) is the most variable part of the mtDNA molecule, which has been chosen to study population structure and diversity in most major taxa of organisms (Wu et al. 2004, 2006, Zhang et al. 2004, Ruan et al. 2005, Wu and Fang 2005, Hu et al. 2006, Xu and Fang 2006). This study aimed to examine for the first time the genetic structure and gene flow among five wild populations of Elliot's Pheasant by detailed analysis of the mtDNA control region sequences. There was an expectation that genetic analysis would prove useful in forming management strategies.

\section{Materials and methods}

\section{DNA extraction, amplification and sequencing}

In total, 33 samples were obtained from five different localities shown in Figure 1: western China site, Leigongshan Nature Reserve in Guizhou (GZ) province; central China site, in Hunan (HN) province; eastern China (three sites), Gutianshan Nature Reserve in Zhejiang (ZJ) province, Ningguo country in Anhui (AH) province, and Fujian (FJ) province. Samples were collected as blood material or pads from feet of dried specimens (Table 1).

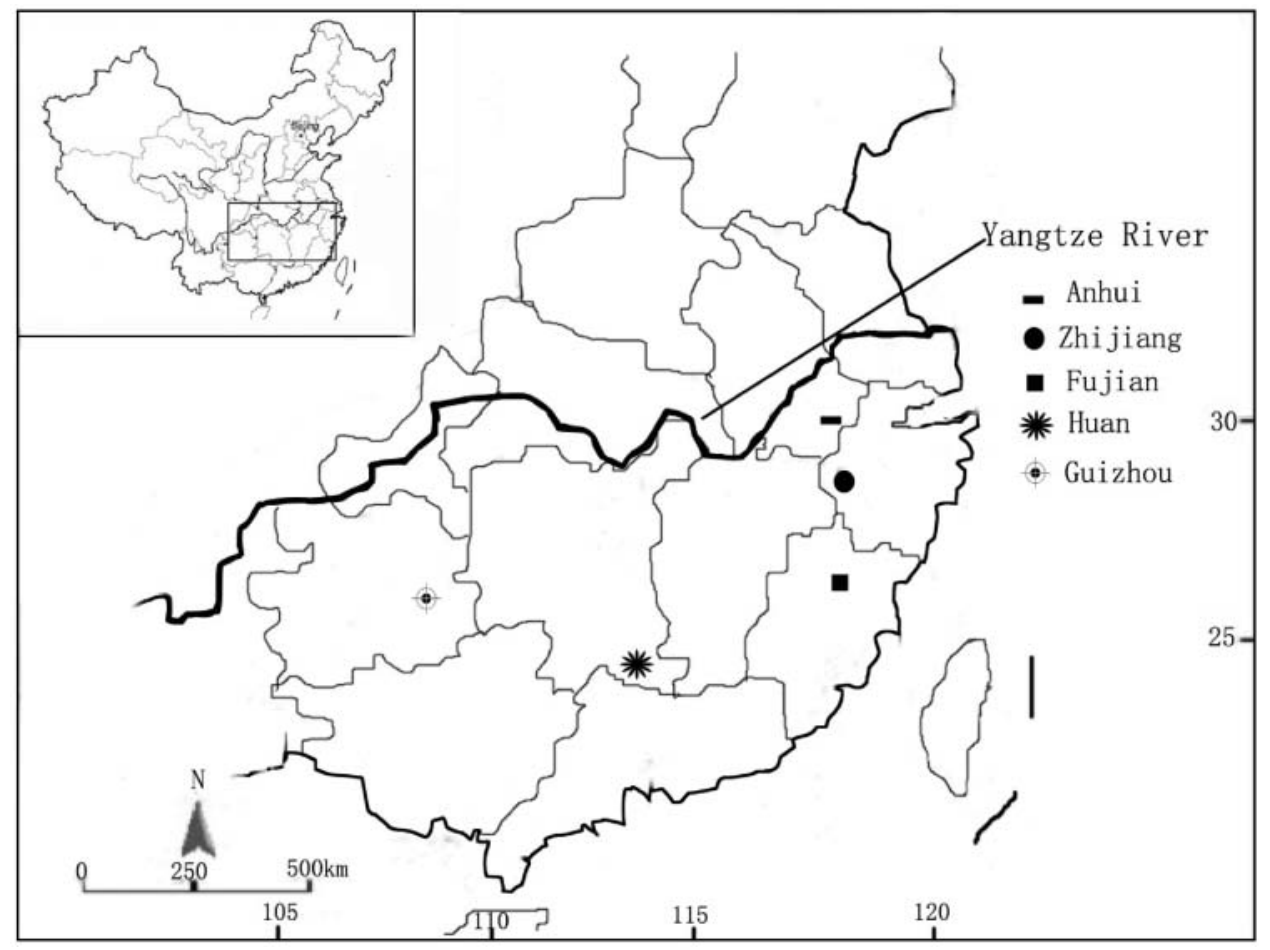

Figure 1. Sampling localities of Elliot's Pheasant. 
Table 1 . Measures of mitochondrial DNA diversity observed in the five populations of Elliot's Pheasant.

\begin{tabular}{lclcll}
\hline Population & $N$ & Individual code & $N_{\mathrm{h}}$ & $h \pm \mathrm{SD}$ & $\pi \pm \mathrm{SD}$ \\
\hline $\mathrm{AH}$ & 6 & AHo1-04, AHo7-08 & 5 & $0.933 \pm 0.122$ & $0.00272 \pm 0.00055$ \\
$\mathrm{ZJ}$ & 5 & ZJo1, ZJo6-08, ZJ10 & 6 & $1.000 \pm 0.126$ & $0.00504 \pm 0.00130$ \\
$\mathrm{FJ}$ & 6 & FJo1-04, FJ07, FJ13 & 6 & $1.000 \pm 0.096$ & $0.00510 \pm 0.00108$ \\
$\mathrm{HN}$ & 7 & HNo1-07 & 6 & $0.952 \pm 0.096$ & $0.00480 \pm 0.00125$ \\
$\mathrm{GZ}$ & 9 & GZo1, GZ03-06, GZ08-11 & 9 & $1.000 \pm 0.052$ & $0.00575 \pm 0.00100$ \\
Total & 33 & & 31 & $0.992 \pm 0.010$ & $0.00616 \pm 0.00055$ \\
\hline
\end{tabular}

$N$, number of individuals; $N_{h}$, number of haplotypes; $h$, haplotype diversity; $\pi$, nucleotide diversity.

Genomic DNA was isolated using standard proteinase $\mathrm{K}$ digestion and phenol/chloroform extraction procedures (Sambrook et al. 1989). Polymerase chain reaction (PCR) amplification was performed in a $50 \mu \mathrm{l}$ reaction volume on a PTC-0220 Peltier thermal cycler using a pair of universal primers: PHDL and PHDH (Randi and Lucchini 1998). The thermal cycling profile, and the DNA fragment cloning and sequencing settings, have been described in detail in Jiang et al. (2005).

\section{Data analyses}

Control region sequences were aligned using the program CLUSTAL X (Thompson et al. 1997) and were checked visually. Two standard measures of genetic diversity - nucleotide diversity $(\pi)$ and haplotype diversity $(h)$ - were calculated using the program DnaSP version 3.5I (Rozas and Rozas 1999). Initial sequence comparisons and measures of variability were performed using $\mathrm{MEGA}_{3}$ (Kumar et al., 2004).

A hierarchical analysis was carried out among groups (a group of pooled $\mathrm{AH}, \mathrm{ZJ}, \mathrm{FJ}$ and $\mathrm{HN}$ populations versus a group of the GZ population) and populations by analysis of molecular variance (AMOVA) analyses (where $\Phi_{C T}$ is the genetic variation attributable to genetic differentiation among groups, $\Phi_{S C}$ that among populations within groups, and $\Phi_{S T}$ that among populations relative to the total sample). AMOVA analyses (Excoffier et al. 1992), values of migrating individuals $(\mathrm{Nm})$ calculated from $F$-statistics $\left(F_{S T}\right)$, were performed in the software package ARLEQUIN version 2.0 (Schneider et al. 2000). $\mathrm{Nm}$ was the historical average number of individual migrants contributing to a population's gene pool each generation, where $N$ was the female effective population size and $m$ was the female migration rate. It was calculated from the equation $F_{S T}=1 /(2 M+1)$ (Slatkin 1987, Baker et al., 1994), where $M=N m$ for haploid populations. To assess the relationship among mtDNA sequences, a phylogenetic tree was constructed with MEGA3 using the maximum parsimony (MP) method, rooted with one homologous sequence from Hume's Pheasant (Syrmaticus humia) as outgroup (GenBank accession number $\mathrm{AY}_{3} 68069$ ). Bootstrapping of 1,000 replicates supported branches.

Historical demography analyses - a size stationary model or a range expansion model - were tested for the four populations. Fu's $F_{S}$ test, its corresponding $P$ values and parameters related to a population growth expansion (where $\tau$ is expansion time, and $\theta_{\circ}$ and $\theta_{1}$ are expansion range) were performed in the software package ARLEQUIN version 2.0 (Schneider et al. 2000). Fu's $F_{S}$ test, which was initially designed as a test of selective neutrality, was very sensitive to population demographic expansion with high negative values ( $\mathrm{Fu} \mathrm{1997).} \mathrm{A} \mathrm{null} \mathrm{model} \mathrm{of}$ population range expansion was assumed if $\tau>0$ and $\theta_{1}>\theta_{0}$ or a null model of population stability if $\tau=$ o or $\theta_{\mathrm{I}}=\theta_{\mathrm{o}}$. Then the validity of the estimated demographic model was tested by the distribution of a $S S D$ test (the sum of squared differences) between the observed and an estimated mismatch distribution, which was obtained by a bootstrap approach. A significant $S S D$ value $(P<0.05)$ was taken as evidence for departure from a model of population range 
expansion (when $\tau>\mathrm{o}$ and $\theta_{1}>\theta_{\mathrm{o}}$ ), or from a model of population stability (when $\tau=\mathrm{o}$ or $\theta_{1}=$ $\theta_{\mathrm{o}}$ ) (Schneider and Excoffier 1999).

\section{Results}

\section{Sequence diversity}

Nucleotide sequence data comprising $1,152-1,154$ base pairs (bp) from the mtDNA control region was collected from 33 individuals of Elliot's Pheasant. The nucleotide composition included $14 \% \mathrm{G}, 26.7 \% \mathrm{~A}, 32.6 \% \mathrm{~T}$ and $26.6 \% \mathrm{C}$, showing a paucity of guanine. This is in agreement with the characteristics of other avian control region sequences (Baker and Marshall 1997), which confirmed that control region sequences and haplotypes obtained in this study were successfully amplified from a true mitochondrial origin rather than from a nuclear pseudogene.

Genetic variability is shown in Table 1 . The mean haplotype diversity $(h)$ of all individuals was 0.992 , ranging from 0.933 to 1.000 , while the mean nucleotide diversity $(\pi)$ was 0.00616 , ranging from 0.00272 to 0.00575 . Thirty-one unique haplotypes were identified from 33 individuals by 55 variable nucleotide positions in the control region sequences. Haplotype $\mathrm{AHO}_{3}$ was shared by both $\mathrm{AH}_{3}$ and $\mathrm{AHo}$ individuals. Haplotype $\mathrm{HNO}_{3}$ was shared by $\mathrm{HNO}_{3}$ and HNo7 individuals. All identified haplotypes are shown in Table 2.

\section{Genetic structure}

Since the GZ population appeared to have a somewhat different genetic structure from other populations in our preliminary analyses, the five populations were pooled into two groups: a group of pooled $\mathrm{AH}, \mathrm{ZJ}, \mathrm{FJ}$ and $\mathrm{HN}$ populations versus a group of the GZ population. The hierarchical analyses enabled a better understanding of the layer (groups, populations or individuals) to which the genetic difference was attributable (Table 3). Differences between two groups $\left(\Phi_{C T}\right)$ explained a larger proportion of the total genetic variance $(33.7 \%)$, but were not significant. Differences among populations within each group $\left(\Phi_{S C}\right)$ explained only $4.42 \%$ of the total genetic variance. On the other hand, differences among populations relative to the total sample $\left(\Phi_{S T}\right)$ explained most of the genetic variance $(61.9 \%)$, which was significant. Shown as the rooted MP tree (Figure 2), most individual sequences were mixed, except sequences from the GZ population which was largely grouped in its own branch.

The number of migrants $\mathrm{Nm}$ among $\mathrm{AH}, \mathrm{ZJ}$ and $\mathrm{FJ}$, as shown in Table 4, was above 10 individuals per generation, indicating a large amount of gene flow. The smallest amount of gene flow appeared between GZ and the other populations, which ranged from 0.73 to 1.39.

\section{Demographic analyses}

Demographic analyses (Table 5) showed evidence of range expansions of the group of pooled $\mathrm{AH}, \mathrm{ZJ}, \mathrm{FJ}$ and $\mathrm{HN}$ populations. Mismatch tests were consistent with a range expansion model in which significant $P$ values for Fu's $F_{S}$ test were obtained. Demographic parameters estimated by mismatch analyses corresponded to a null model of population range expansion $\left(\tau>0\right.$ and $\theta_{1}>$ $\theta_{\mathrm{o}}$ ) that could not be rejected (the sum of squared differences' $P$ values $>0.05$ ).

\section{Discussion}

\section{Genetic structure}

These results suggested a high level of haplotype variation in wild populations of Elliot's Pheasant. A quite substantial degree of genetic structure was revealed, since $33.7 \%$ of the variation was distributed among groups (GZ population relative to all others pooled), though it 
Table 2. Thirty-one mitochondrial haplotypes resolved from 33 individuals of Elliot's Pheasant.

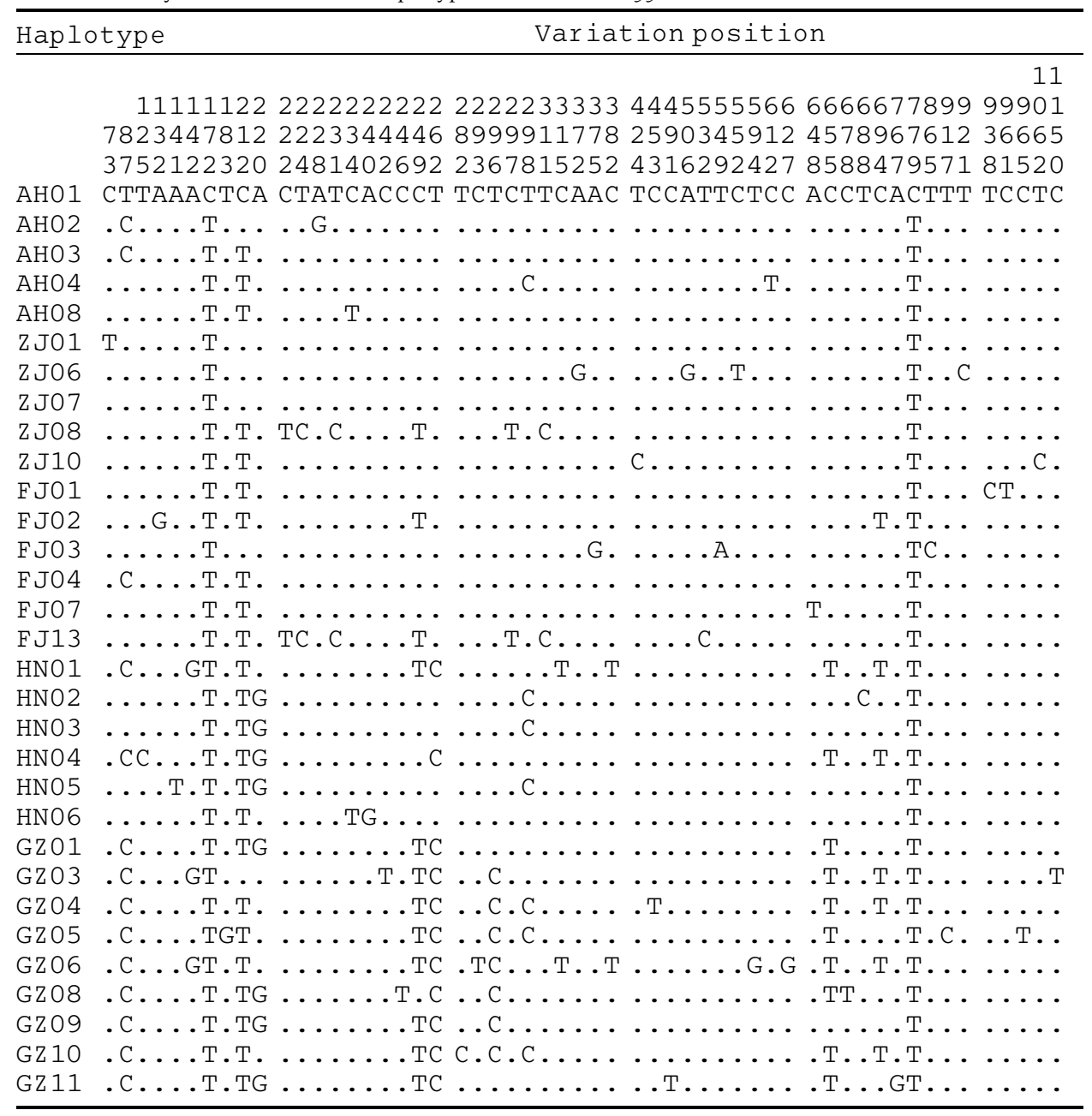

Note. Position numbers (read vertically) refer to the location of each variable site in the sequence. Dots indicate similarity with haplotype AHo1, and letters indicate base substitutions. Here, samples codes are used as haplotypes codes.

Table 3. Analysis of molecular variance (AMOVA) analyses for Elliot's Pheasant grouped into a group of $\mathrm{AH}, \mathrm{ZJ}, \mathrm{FJ}$ and $\mathrm{HN}$ versus the GZ group.

\begin{tabular}{ll}
\hline Source of variation & Elliot's Pheasant \\
\hline Among groups & $33.7 \%$ \\
Among populations within groups & $4.42 \%$ \\
Within populations & $61.88 \%$ \\
$\Phi_{C T}=$ & $0.337(P=0.20)$ \\
$\Phi_{S C}=$ & $0.067(P=0.01)$ \\
$\Phi_{S T}=$ & $\mathbf{0 . 3 8 1}(\boldsymbol{P}<\mathbf{0 . 0 0 1})$ \\
\hline
\end{tabular}

$\Phi_{C T}$ represents the amount of genetic variation attributable to genetic differentiation among group; $\Phi_{S C}$ that among populations within groups; and $\Phi_{S T}$ that among populations relative to the total sample. Values in bold indicate significance at $\mathrm{P}<0.001$ (10,100 permutations). 


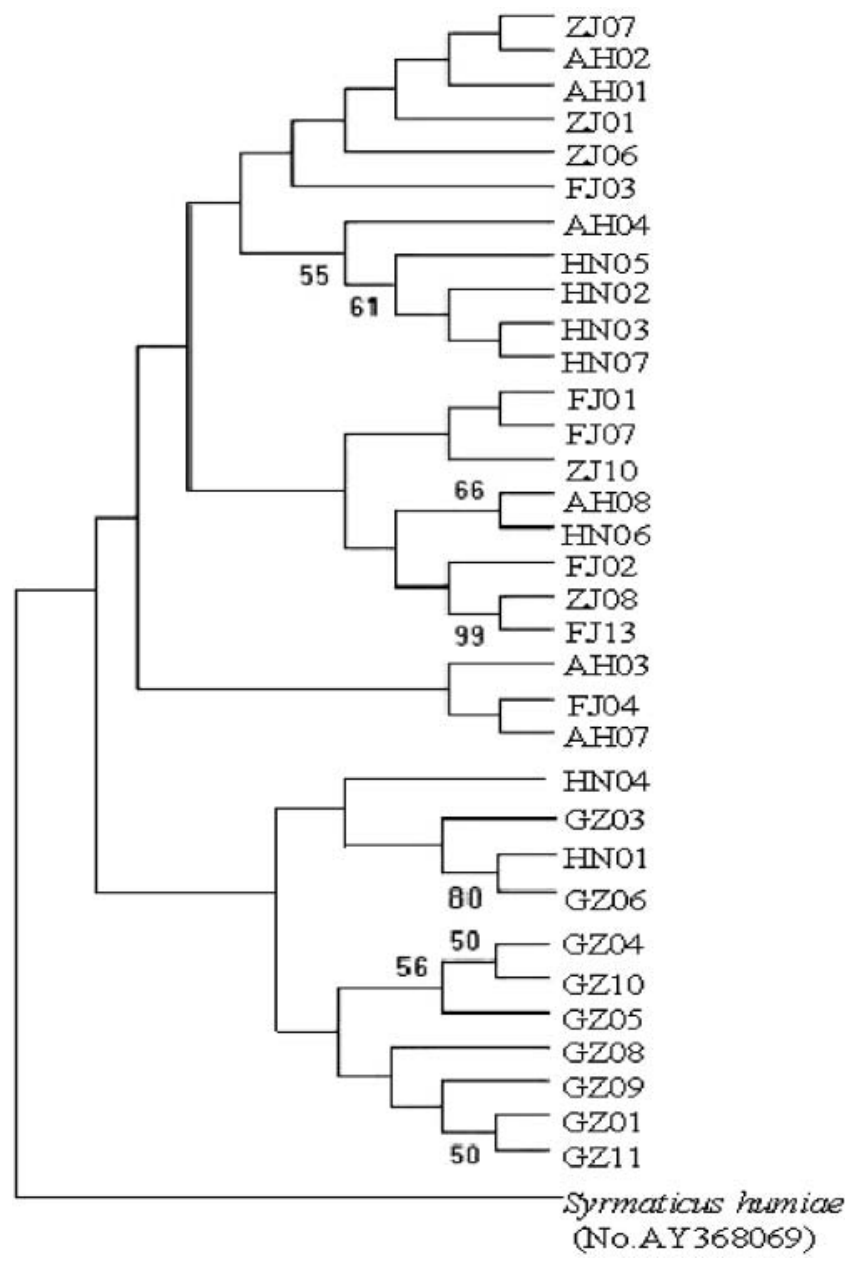

Figure 2. Phylogenetic relationships among the $33 \mathrm{mtDNA}$ control region sequences constructed using maximum parsimony, rooted with a control region sequence of Syrmaticus humiae (GenBank accession number AY368069).

was not statistically significant in the AMOVA analysis. Furthermore, sequences of the GZ population were largely grouped in their own branch, while sequences of the remaining four populations were interspersed among branches. So what accounted for the different genetic

Table 4. Population pairwise $F_{S T}$ values (lower left matrix) and the number of migrants (Nm, upper right matrix).

\begin{tabular}{llllll}
\hline & AH & ZJ & FJ & HN & GZ \\
\hline AH & & 10.00 & 40.5 & 3.34 & 0.74 \\
ZJ & 0.048 & & infinite & $\mathbf{2 . 3 4}$ & 0.73 \\
FJ & 0.012 & -0.054 & & 3.85 & 0.90 \\
HN & 0.130 & 0.176 & 0.115 & & 1.39 \\
GZ & $\mathbf{0 . 4 0 3}$ & $\mathbf{0 . 4 0 7}$ & $\mathbf{0 . 3 5 7}$ & $\mathbf{0 . 2 6 5}$ & \\
\hline
\end{tabular}

Significant $F_{S T}$ values are indicated in bold type $(P<0.001$, 10,000 permutations). 
Table 5. Demographic test to detect historical range expansion.

\begin{tabular}{llllll}
\hline Group & $\boldsymbol{F}_{S}{ }^{*}$ & $\tau$ & $\theta_{o}$ & $\theta_{1}$ & SSD $^{\#}$ \\
\hline AH, ZJ, FJ, HN pooled & $-\mathbf{1 7 . 7}$ & 3.44 & 2.10 & 7101 & $\mathbf{0 . 0 0 4}$ \\
\hline
\end{tabular}

Both $F_{S,}$ and $S S D$ values in bold are statistically significant $\left({ }^{*} P<0.001,{ }^{\#} P=0.60\right)$ and consistent with a model of range expansion.

structure of the GZ population? Lower level of gene flow serves as a factor. The average estimate of gene flow between the GZ population and the remaining four populations suggested limited exchange among populations. Ding (1998) deduced that the ancestor of Syrmaticus in China originated from the Wuling Mountainous Area, which extended from north-east Guizhou province to the south-west. The Wuling Mountainous Area (mean elevation 1,00o m) serves as a natural barrier between Guizhou and Hunan provinces. Elliot's Pheasant, with its limited dispersal ability, seems unable to cross it, leading to a lower number of migrants from the GZ population to the remaining four populations, since it mainly inhabits an elevation of $300-800 \mathrm{~m}$ in broad-leaved or mixed forest. Moreover, Johnsgard (1986) commented that Elliot's Pheasant was separated from Bar-tailed Pheasant (Syrmaticus humia) in the eastern Himalayas. Was the western habitat a refuge for ancient Elliot's Pheasant? It would require a complete phylogeny of the genus with appropriate outgroups to support this.

In contrast, little population structure was indicated among the remaining four populations. In this study, the $\mathrm{Nm}$ values among these four populations detected an extent of gene flow with a large number of migrants between connected sites, which are all located in the middle and lower reaches of the Yangtze River plain. Therefore, it is suggested that gene flow is sufficient to homogenize gene pools among the four populations. Secondly, population expansion, a historic demographic pattern, was another plausible explanation for the lack of genetic structure in the four populations. The demographic parameters estimated by mismatch analyses corresponded to a model of population range expansion. The idea of population expansion was further supported by the significantly negative $\mathrm{Fu}^{\prime}{ } F_{S}$ value.

\section{Conservation implications}

A good understanding of population genetic structure is critical to the design of an effective conservation programme for this species. Based on the substantial genetic differentiation among populations, the GZ population would be considered as one Management Unit (Moritz 1994). If a conservation programme aims to preserve the genetic distinctiveness of the species in the west of China, artificial introductions of Elliot's Pheasant from AH, ZJ, FJ and HN populations to the GZ population should be discouraged. Additional study should be focused on the GZ population regarding its origin, evolution, etc. Since gene flow and other genetic parameters are indicators of the cumulative evolutionary process, the "current" genetic structure is the result of past evolution. Recent habitat loss, fragmentation and degeneration would therefore have more negative effects on the future population genetic structure. The much reduced habitat has been further fragmented into smaller patches in recent decades (BirdLife International 2006) and, given the declining population, habitat management is seen as vital because demography and genetics are not independent.

\section{Acknowledgements}

This work was supported by grants from the National Natural Science Foundation of China (30170144 and 30470232), and by a special grant for Elliot's Pheasant from the State Forestry Administration, P. R. China. The manuscript benefited from the comments and advice of Prof. Sheng-Guo Fang, Dr Qiu-Hong Wan, Chris Wood, Dr Stuart Marsden and Dr Brant Faircloth. 
We also thank Shui-Hua Chen, Wei Liang, Xue-Jian Deng, Li Li and Bo-Feng Liu for their assistance in obtaining samples.

\section{References}

Avise, J. C. (200o) Phylogeography: the history and formation of species. Cambridge, MA: Harvard University Press.

Baker, A. J. and Marshall, H. D. (1997) Mitochondrial control region sequences as tools for understanding evolution. Pp. $51-82$ in D. P. Mindell, ed. Avian molecular evolution and systematics. San Diego, CA: Academic Press.

Baker, C. S., Slade, R. W. and Bannister, J. L. (1994) Hierarchical structure of mitochondrial DNA gene flow among humpback whales Megaptera novaeangliae, worldwide. Mol. Ecol. 3: 313-327.

BirdLife International (2006) Species factsheet: Syrmaticus ellioti. Downloaded from http://www.birdlife.org on 25 May 2006.

Delacour, J. (1977) The pheasants of the world. London: Country Life and Allen Publishing.

Ding, P. (1998) The distributions and systematic analysis of the Elliot's pheasant. Chinese Life Sci. Res. 2: 22-131.

Ding, P. and Jiang, S. R. (2000) Fragmentation study of Elliot's pheasant in the west of Zhejiang province. Chinese Zool. Res. 21: 65-69.

Ding, P. and Zhuge, Y. (1988) The ecology of Syrmaticus ellioti Swinhoe. Acta Ecol. Sinica 8: 44-50 (In Chinese.).

Ding, P., Zhuge, Y. and Zhang, C. Z. (1990) The studies on breeding ecology of Syrmaticus ellioti Swinhoe. Chinese Zool. Res. 11: 139-145 (In Chinese.).

Excoffier, L., Smouse, P. E. and Quattro, J. M. (1992) Analysis of molecular variance inferred from metric distances among DNA haplotpes: application to human mitochondrial DNA restriction data. Genetics 131: 479-491.

Fu, Y. X. (1997) Statistical tests of neutrality of mutations against population growth, hitchhiking and background selection. Genetics 147: 915-925.

Hu, J., Fang, S. G. and Wan, Q. (2006) Genetic diversity of Chinese water deer
(Hydropotes inermis inermis). Biochem. Genet. DOI: 101007/s10528-006-9020-7.

Jiang, P. P., Fang, S. G. and Ding, P. (2005) An application of control region sequence as a matrilineage marker for Elliot's Pheasant of a zoo population. Anim. Biotechnol. 16: 11-15.

Johnsgard, P. A. (1986) The pheasants of the world. Oxford: Oxford University Press.

Knoder, C. E. (1983) Elliott's Pheasant conservation. World Pheasant Assoc. J. 8: 11-28.

Kvist, L., Ruokonen, M., Lumme, J. and Orell, M. (1999) The colonization history and present-day population structure of the European great tit (Parus major major). Heredity 82: 495-502.

Kumar, S., Tamura, K. and Nei, M. (2004) MEGA $_{3}$ : integrated software for molecular evolutionary genetics analysis and sequence alignment. Briefings Bioinform. 5: 150-163.

Laurent, R. S., Legault, M. and Bernatchez, L. (2003) Divergent selection maintains adaptive differentiation despite high gene flow between sympatric rainbow smelt ecotypes (Osmerus mordax Mitchill). Mol. Eco l.12: 315-330.

Long, D. Z. (1985) Ecology of Elliot's Pheasant. Chinese Wildlife 1: 24-25.

Moritz, C. (1994) Defining evolutionary significant units for conservation. Trends Ecol. Evol. 9: 373-375.

Newton, I., ed. (2003) The speciation and biogeography of birds. London: Academic Press.

Peng, Y. B. and Ding, P. (2005) Factors affecting movement of spring dispersal of Elliot's Pheasants. Chinese Zool. Res. 26: 373-378.

Randi, E. and Lucchini, V. (1998) Organization and evolution of the mitochondrial DNA control region in the avian genus Alectoris. J. Mol. Evol. 47: 449-462.

Rozas, J. and Rozas, R. (1999) DnaSP version 3: an integrated program for molecular 
population genetics and molecular evolution analysis. Bioinformatics 15: 174-175.

Ruan, X. D., He, P. J., Zhang, J. L., Wan, Q. H. and Fang, S. G. (2005) Evolutionary history and current population relationships of the chiru (Pantholops hodgsonii) inferred from mtDNA variation. J. Mammal. 86: 881-886.

Sambrook, J., Fritsch, E. F. and Maniatis, T. (1989) Molecular cloning: a laboratory manual.. Second edition. Cold Spring Harbor, NY: Cold Spring Harbor Laboratory Press.

Schneider, S. and Excoffier, L. (1999) Estimation of past demographic parameters from the distribution of pairwise differences when the mutation rates vary among sites: application to human mitochondrial DNA. Genetics 152: 1079-1089.

Schneider, S., Roessli, D. and Excoffier, L. (2000) ARLEQUIN, a software for population genetics data analysis, version 2.0oo. Geneva, Switzerland: Genetics and Biometry Laboratory, University of Geneva.

Shi, J. B. and Zheng, G. M. (1997) The seasonal changes of habitats of Elliot's Pheasant. Chinese Zool. Res. 18: 275-283.

Slatkin, M. (1987) Gene flow and the geographic structure of natural populations. Science 236: 787-792.
Thompson, J. D., Gibson, T. J., Plewniak, F., Jeanmougin, F. and Higgins, D. G. (1997) The ClustalX windows interface: flexible strategies for multiple sequence alignment aided by quality analysis tools. Nucleic Acids Res. 24: 4876-4882.

$\mathrm{Wu}, \mathrm{H}$. L. and Fang, S. G. (2005) Mitochondrial DNA genetic diversity of Black Muntjac (Muntiacus crinifrons): an endangered species endemic to China. Biochem. Genet. 43: 407-416.

Wu, H. L., Wan, Q. H. and Fang, S. G. (2006) Population structure and gene flow among wild populations of the Black Muntjac (Muntiacus crinifrons) based on mitochondrial DNA control region sequences. Zool. Sci. 23: 333-340.

Wu, H., Wan, Q. H. and Fang, S. G. (2004) Two genetically distinct units of the Chinese sika deer (Cervus nippon): analyses of mitochondrial DNA variation. Biol. Conserv. 119: 183-190.

$\mathrm{Xu}$, Q. H. and Fang, S. G. (2006) Variable number tandem repeats in the mitochondrial DNA control region of the Chinese Alligator, Alligator sinensis. AmphibiaReptilia 27: 93-101.

Zhang, B., Fang, S. G. and Xi, Y. M. (2004) Low genetic diversity in endangered Crested Ibis Nippon nippon and implications for conservation. Bird Conserv. Int. 14: 183-190.

\section{PING PING JIANG, YUN FA GE, QIU LEI LANG, PING DING* \\ College of Life Sciences, Zijingang Campus of Zhejiang University, Hangzhouz10058, Hangzhou, P. R. China, and State Conservation Centre for Gene Resources of Endangered Wildlife, and Key Laboratory of Conservation Genetics and Reproductive Biology for Endangered Wild Animals of the Ministry of Education, Zhejiang Province, P. R. China.}

*Author for correspondence; e-mail: dingping@zju.edu.cn 